\title{
Heidrun Ochs, Gabriel Zeilinger (dir.), Kaufhäuser an Mittel- und Oberrhein im Spätmittelalter
}

\section{Corentin Hamet}

\section{OpenEdition}

\section{Journals}

Édition électronique

URL : http://journals.openedition.org/ifha/10495

DOl : $10.4000 /$ ifha. 10495

ISSN : 2198-8943

Éditeur

IFRA - Institut franco-allemand (sciences historiques et sociales)

Référence électronique

Corentin Hamet, « Heidrun Ochs, Gabriel Zeilinger (dir.), Kaufhäuser an Mittel- und Oberrhein im

Spätmittelalter », Revue de l'IFHA [En ligne], Date de recension, mis en ligne le 15 janvier 2020, consulté

le 24 septembre 2020. URL : http://journals.openedition.org/ifha/10495 ; DOI : https://doi.org/

10.4000/ifha. 10495

Ce document a été généré automatiquement le 24 septembre 2020.

(C)IFHA 


\title{
Heidrun Ochs, Gabriel Zeilinger (dir.), Kaufhäuser an Mittel- und Oberrhein im Spätmittelalter
}

\author{
Corentin Hamet
}

Le présent ouvrage constitue la publication des actes d'un colloque tenu à Mayence les 3 et 4 mars 2016 et portant sur les Kaufhäuser (le français parle tantôt de « halle » tantôt de « douane ", notamment en Alsace) dans l'espace du Rhin supérieur et du Rhin moyen à la fin du Moyen Âge. Il s'inscrit ainsi les travaux de recherches autour de la halle de Mayence ayant donné lieu à la création d'un site internet (www.regionalgeschichte.net/rheinhessen/mainz/kulturdenkmaeler/kaufhaus-ambrand/startseite.html) et à diverses publications. Le but affiché des organisateurs était de dépasser le cas mayençais et de le mettre en perspective dans le cadre d'une histoire régionale comparée. Le volume rassemble ainsi les contributions de sept chercheurs, encadrées par une introduction cernant les enjeu thématiques et historiographiques du sujet et une conclusion formant synthèse, rédigée par Uwe Israel.

La contribution de Nina Gallion revient tout d'abord sur le contexte d'émergence des halles dans la région du Bodensee à partir du XIV ${ }^{\mathrm{e}}$ siècle avant de détailler le fonctionnement des halles de Constance et de Fribourg en Brisgau et les diverses fonctions qu'elles ont connues dès le Moyen Âge. Dans une perspective similaire, Olivier Richard étudie les halles alsaciennes en montrant leur diffusion mais en s'attardant également sur leur place centrale dans la ville et en faisant le lien entre le bâtiment et les nombreuses institutions qui gravitent autour de lui. Le recours à la notion d'espace publique lui permet de présenter la halle comme un instrument de démonstration du pouvoir municipal, et comme un espace aussi inclusif qu'exclusif. Raoul Hippchen porte son attention plus au nord, sur la région du Rhin supérieur, où il identifie les halles (de façon peut-être un peu trop restrictive) et montre à quel point elles pouvaient représenter un enjeu politique pour les seigneurs territoriaux et les autorités urbaines. L'auteur n'hésite pas à évoquer une politique économique urbaine, dont la halle serait le support. 
Kurt Weissen et Joachim Schneider adoptent une autre approche, donnant à voir pardelà les sources normatives la perspective des acteurs sur l'institution. Le premier nous livre, avec un luxe de détails que seules permettent les sources bâloises, l'activité des différents personnels en mettant en relief les dysfonctionnements survenus au sein de l'institution, rendant sa complexité et sa vie au quotidien de la halle. Le second, mobilisant tous les documents disponibles (chroniques, récits de voyages, descriptions de villes...), s'est attaché à retrouver le regard que les contemporains portaient sur elle. Julia von Ditfurth, de son côté, tente de définir les caractéristiques architecturales des halles médiévales dans un panorama fouillé des bâtiments les plus connus du sud-ouest de l'Allemagne analysés au prisme de leur forme. On s'étonne enfin de trouver une contribution sur les halles dans l'espace hanséate dans une publication consacrée à l'espace rhénan. Elle a ici le mérite d'élargir la perspective et de souligner les particularités propres à cette région en explicitant l'absence de halles dans certaines villes comme un choix délibéré, opéré par les autorités urbaines et les marchands. L'ouvrage n'échappe pas à de prévisibles répétitions concernant Fribourg en Brisgau ou Constance, qui sont des exemples bien connus des auteurs allemands. Celles-ci reflètent peut-être la difficulté de travailler sur des régions rhénanes autrefois parties intégrantes d'un empire, actuellement partagées entre trois pays. Qu'un auteur français ait présenté le cas alsacien, un Suisse, le cas bâlois et cinq Allemands la situation dans leur pays dans un même livre traduit autant l'heureuse volonté d'écrire l'histoire d'un espace aujourd'hui transfrontalier que ses limites.

Le choix d'aborder la thématique en faisant l'histoire d'un bâtiment et en considérant la halle comme un lieu unique avait l'avantage de jeter un éclairage sur les différentes fonctions de celui-ci mais reléguait au second plan la halle comme institution, matérialisée, en réalité, par plusieurs édifices dans une topographie mouvante et réticulaire. Celle-ci dépasse de loin les seules constructions encore aujourd'hui visibles et si bien illustrées au fil des pages ; une définition introductive plus aiguisée aurait permis d'ouvrir le débat et d'offrir une vision complexifiée et plus dynamique. Restant sur sa faim, le lecteur pouvait notamment espérer voir analysé le rôle de la balance et des poids et mesures, dont la halle n'apparait ici, tout au plus, que comme le réceptacle. La variation des rythmes d'activités, dans une région marquée par les foires de Strasbourg, de Bâle et par celles aussi proches que considérables de Francfort, aurait également pu être soulignée. Cependant, sept contributions ne pouvaient à elles seules épuiser le débat ; elles incitent au contraire à son actualisation et à son renouvellement.

\section{INDEX}

Index chronologique : Moyen Âge

Thèmes : Histoire des villes et des régions ; Histoire économique ; Histoire de l'art 
AUTEUR

CORENTIN HAMET

EHESS/Université de Heidelberg 